\title{
Qual Formação no Trabalho Educativo com a Primeira Infância?
}

\author{
Agnese Infantino' \\ 'Universitá Degli Studi Milano Bicocca, Milão - Itália
}

RESUMO - Qual Formação no Trabalho Educativo com a Primeira Infância? Uma ênfase sobre reflexividade, na formação das profissões da primeira infância, expõe tanto ao risco de desvalorizar a dimensão da prática quanto ao de supervalorizar a individualidade de cada profissional reflexivo. Estes riscos são elevados na formação das profissões da primeira infância onde são essenciais as práticas educativas, o grupo profissional, a cultura da instituição educativa. Quais abordagens praticar para a formação destas profissões? Os modelos montessoriano e pikleriano, a didática profissional, a pedagogia interativa e a formação na prática.

Palavras-chave: Formação. Profissões Educativas. Primeira Infância. Práticas Educativas.

ABSTRACT - Which Teacher Training for Early Childhood Educators? Emphasis on reflexivity, in the training of early childhood educators, exposes one both to the risk of devaluing the practical dimension as well as to overestimating the individuality of each reflective practitioner. These risks are high in the training of early childhood education professionals, where educational practices, the professional group and the culture of the service are essential. Which approaches should be used in training for these professions? Montessorian and Piklerian models, professional didactics, interactive pedagogy and training in the field.

Keywords: Education. Teaching Professions. Early Childhood. Education Practices.

Educação \& Realidade, Porto Alegre, v. 40, n. 4, p. 987-1004, out./dez. 2015. 987 http://dx.doi.org/10.1590/2175-623651715 
Qual Formação no Trabalho Educativo com a Primeira Infância?

\section{Introdução}

\section{O Sucesso do Profissional Reflexivo}

O profissional reflexivo encarna o perfil que de forma sempre recorrente, é perseguido por várias abordagens e experiências formativas $^{1}$. É de fato reconhecida por várias fontes a necessidade de sustentar com fundada convicção reflexiva as intervenções de natureza prática que todos os profissionais colocam em ação, no seu trabalho, qualquer que ele seja. Pensar naquilo que se faz, ter consciência das razões teóricas e conceituais que sustentam as intervenções é, evidentemente, um objetivo profissional - e formativo; imprescindível. Se, em seguida, nos interessarmos à área específica das profissões educativas que atuam no âmbito da primeira infância, então esta exigência parece ainda mais peremptória. Que as intervenções e os comportamentos postos em ação por uma educadora não sejam simplesmente o êxito de uma predisposição inata, de um instinto materno ou de uma espontânea e irrefletida sensibilidade pessoal, mas, ao contrário, colocar em ação escolhas profissionais fundadas teoricamente, ponderadas e deliberadamente pensadas é um objetivo importante no trabalho formativo, que concorre a definir a densidade e a dignidade profissional de uma figura - aquela da educadora - que ainda muito frequente, sobretudo no senso comum, não tem seu pleno valor reconhecido.

Não se pode, portanto, senão acolher positivamente o sucesso e a crescente difusão de modelos e abordagens formativas centradas na reflexividade e na busca da consciência profissional. Todavia pode ser ao mesmo tempo interessante parar para considerar de modo mais analítico estas orientações formativas abrangendo alguns temas e questões que merecem ser olhados mais de perto e postos em relação à peculiaridade da formação orientada às profissões que atuam com a primeiríssima infância.

Nesta perspectiva pode, portanto, ser útil iniciar um discurso deixando-se guiar por uma primeira interrogativa: em que sentido reflexividade?

São famosas a este respeito as contribuições de Schön (1983; 1987). Com a imagem do profissional reflexivo, Schön condensa uma série de considerações que giram em torno à centralidade do conceito de reflexividade e, mas genericamente, sobre a ideia de uma nova epistemologia da prática profissional, fundada no rigor do pensamento que nasce e se desenvolve na ação no campo de atuação. O profissional de que fala Schön tem a capacidade de manter aberto um diálogo crítico com a realidade dos fenômenos que se apresentam à sua atenção profissional, e sabe constantemente adaptar e modelar os conhecimentos teóricos em função das exigências específicas expressas por cada caso, por cada situação problemática, cada vez em forma diferente. Neste sentido, o primeiro passo reflexivo que cada profissional cumpre se dirige à defi-

988 Educação \& Realidade, Porto Alegre, v. 40, n. 4, p. 987-1004, out./dez. 2015. 
nição, construção do problema, com a intenção de dar um sentido, uma ordem profissionalmente compreensível à aparição caótica e disforme com a qual os fenômenos se apresentam na realidade. De fato,

\begin{abstract}
[...] na realidade e na prática, os problemas não se apresentam ao profissional como dados. Eles devem ser construídos a partir dos materiais de situações problemáticas que são desconcertantes, perturbadoras, incertas. Para transformar uma situação problemática em um problema, o profissional deve desempenhar um certo tipo de trabalho. Deve compreender uma situação incerta que inicialmente parece incompreensível (Schön, 1983, p. 67).
\end{abstract}

O pensamento que se exercita no curso da ação é aquela forma de raciocínio que se desenvolve nesta dinâmica e que, nascido da ação, tem a finalidade de continuar conectado e sintonizado com a própria ação que o profissional escolherá de colocar em ação. Como de fato afirma Schön,

[...] a reflexão abre a estrada ao experimento na prática. Nós pensamos e realizamos novas ações intencionais para observar os fenômenos que nos surgem como novos, para verificar as nossas tentativas de compreendê-los ou afirmar as condutas que inventamos para mudar as coisas para melhor (Schön, 1987, p. 61).

Este apelo à dimensão experimental do pensamento, que alude, portanto, ao valor hipotético das estratégias que se ativam no campo de atuação e ao ato criativo e original das soluções idealizadas, parece particularmente relevante quando se consideram os contextos de trabalho específicos nas instituições educativas para a primeira infância, nos quais o pessoal educativo é constantemente solicitado por uma multiplicidade de elementos e variáveis em jogo, que podemos encontrar uma combinação de sentidos quando as educadoras conseguem conduzir intervenções profundamente sintonizadas com as necessidades das diversas crianças presentes e envolvidas na situação. A intervenção educativa que toma assim forma não pode ser acolhida como a direta tradução de um postulado teórico, mas parece mais como o êxito não definitivo, mas em transformação de uma série de avaliações e considerações reflexivas que a educadora desenvolve no tempo exato e que a conduzirá na tomada de um caminho e não de um outro, tendo em conta a experiência obtida em situações similares ocorridas em outros momentos. A reflexividade é a forma de pensamento que acompanha e orienta a ação prática, tornando-a pensada e fundada conscientemente, apesar de frequentemente os profissionais que trabalham deste modo expressarem que "[...] se sentem profundamente em dificuldade porque não são capazes de dizer o que é que sabem fazer, nem são capazes de justificar a qualidade ou o rigor daquilo que fazem”. Às vezes - e é um caso recorrente entre os/as educadores/as competentes - esforçam-se 
Qual Formação no Trabalho Educativo com a Primeira Infância?

para reconhecer em termos de saber e de conhecimento os comportamentos profissionais postos em ação, reconduzindo-os à ordem do óbvio. Isto nos assinala, por via empírica, o que demonstrou lucidamente com suas contribuições Bourdieu (1980), ou seja, que o pensamento reflexivo é dotado de uma própria gramática e de uma própria lógica, de natureza prática, precisamente, que não pode ser expressa pelo código verbal e nem mesmo pela linguagem teórica. Trata-se de um pensamento que se pode expressar e obter atuando, isto é, no momento presente dos contextos educativos e observando o fluir dos comportamentos profissionais das/os educadoras/es experientes, que revelam o saber prático a que se referem não tanto mediante o discurso, mas no momento presente da ação profissional. Se, portanto, interessa evidenciar e compreender o pensamento prático das/dos educadoras/es, é necessário recompor através da perspectiva destas a ação educativa efetuada na prática, levando sempre em primeiro plano as escolhas práticas e as estratégias de ação que foram conduzidas. Como no exemplo que segue, extraído de uma experiência de adaptação à creche:

O menino (25 meses) está acompanhado nestes dias de adaptação, pelo pai. São muito ligados, no primeiro dia ficaram muito perto um do outro, o menino procura ir em direção à saída, não me olhava e não se afastava de seu pai. Perguntei a mim mesma o que fazer para fazê-los se sentirem à vontade, convidei o pai a sentar-se deixando que o menino se movesse no ambiente segundo seus próprios tempos. O menino porém, assim que eu me aproximava se escondia entre os braços do pai. Pensei então de propor uma atividade de leitura ao grupo de crianças e enquanto eu lia olhava de modo discreto para o lado do menino e percebi que ele começava a se mover, tocando alguns brinquedos. O grupo de crianças prosseguiu a leitura autonomamente e assim eu pude me aproximar do menino que continuava a me ignorar até que entrou em um túnel e dali me olhava. Sentei-me no chão também e iniciei com o menino o jogo do 'achou!'. Olhava-me, mas assim que nossos olhares se cruzavam corria para o pai. Instauramos, porém um primeiro contato.

Se tivéssemos que pedir à educadora envolvida nesta sequência para exibir, por via conceitual, ou para fundamentar em termos discursivos o modelo teórico a que faz referência, ou o raciocínio que a guiou na condução desta dinâmica relacional, provavelmente a induziríamos a uma condição de silêncio constrangedor, provando a dificuldade de colocar em palavras uma complexa rede de ação-raciocínio na prática, ou de inteligência em ação para usar uma expressão de Scribner (1997). Um hábil profissional, uma educadora competente frequentemente não sabe dizer por que está fazendo exatamente daquele modo e não de um outro, embora possa estar convencida da fundamentação e da eficácia da intervenção. Sabe o que e como fazer, mas nem sempre é capaz de argumentar as razões. Isto acontece porque a eficácia e a pertinência da intervenção profissional não se funda exclusivamente em um conjunto de conhecimentos teóricos possíveis de se dizer e explicitar, mas em uma forma de raciocínio reflexivo que se manifesta conjuntamente

990 Educação \& Realidade, Porto Alegre, v. 40, n. 4, p. 987-1004, out./dez. 2015. 
com a dimensão prática e que, sem esta, é um pouco como se declinasse, talvez porque é um raciocínio, aquele reflexivo, que não tem vida própria, como acontece, ao contrário, à reflexão de natureza teórica, mas tem necessidade da prática para desenvolver-se: vive e de desenvolve junto a esta. É raciocínio prático.

Ainda assim, se se analisa a breve sequência descrita, emerge toda a sua complexidade de uma intervenção profissional em que a educadora pensou e agiu simultaneamente em várias linhas (criança, relação adulto progenitor, condução do grupo das outras crianças presentes); também nesta trama, entre níveis de interação diferentes, reside a peculiaridade do raciocínio prático no trabalho educativo, solicitando às educadoras uma rápida adaptação de perspectiva da dimensão individual àquela do grupo, da ativação de um papel mais orientado ao envolvimento a um outro mais projetado à observação à distância. Ocorrem muitas coisas nas dinâmicas relacionais e se trata de tomar decisões em tempo real, com um raciocínio prático que une velozmente avaliação-hipótese de intervenção-ação-reprojetação que se articulam, nem sempre em modo linear, em uma sequência frenética que pede uma rápida sintonização com a realidade.

O raciocínio reflexivo pode ser reconstruído a posteriori, baseando-se em uma reevocação mediante documentação, mas correndo assim o risco de minimizar o peso do raciocínio e de captá-lo segundo modalidades de análise que são próprias do raciocínio teórico e conceitual, que não atua diretamente na ação, com a prática, mas com as ideias. Se o raciocínio especulativo pode então ser recomposto no fluir concatenado de pensamentos e ideias conectados logicamente entre eles, o raciocínio prático, ao contrário, foge a este tipo de linearidade e se caracteriza por um proceder horizontal, que leva em consideração mais de um elemento por vez, não somente para frente como também para trás, reconsiderando decisões tomadas para modificá-las. É o quanto emerge do exemplo citado, em que mais de um nível se desenvolve paralelamente (a relação educadora-menino-progenitor e, concomitantemente, a relação educadora-grupo de crianças) e nos quais várias estratégias de intervenção são adotadas em busca da intervenção que, naquela específica situação, possa ter um efeito positivo. Aquele $f a$ zer pensativo de que fala também Mortari (2010) se caracteriza por uma atitude de contínua reflexão sobre os próprios passos ao assumir uma postura crítica em relação ao próprio agir.

Se tentarmos circunscrever as especificidades do raciocínio prático no trabalho educativo, devemos, todavia, prestar atenção também a uma outra dimensão de absoluto relevo: a do grupo de trabalho no qual é inserida a intervenção de cada profissional, de cada educadora. Nas instituições educativas, de fato, sejam creches ou organizações de outra tipologia, nunca estão presentes somente as educadoras, mas também estão presentes grupos de trabalho inteiros e compostos de figuras com perfis profissionais diversos. Apresenta-se a este propósito um proble- 
Qual Formação no Trabalho Educativo com a Primeira Infância?

ma inédito para a perspectiva - até aqui percorrida - do raciocínio prático individual, isto é, aquele raciocínio pedagógico compartilhado que toma forma em práticas profissionais fundadas numa cultura educativa própria da estrutura na qual os vários profissionais trabalham. Não é suficiente, pois, que cada profissional, que cada educadora, saiba aprimorar uma prática pensada, construindo próprios modelos intuitivos a partir da experiência educativa na área de atuação; é necessário, para que a intervenção de cada educadora tenha significado, que se criem condições de compartilhamento e acordo a respeito de algumas práticas educativas, capazes de exprimir coerentemente um raciocínio prático comum. Como se desenvolve o pensamento reflexivo no contexto do trabalho de grupo? Quando são vários profissionais a atuarem em um mesmo contexto de trabalho, quais dinâmicas acompanham o raciocínio prático? Podemos falar de um raciocínio prático coletivo? $\mathrm{E}$ quais dinâmicas formativas podem sustentá-lo?

Sobre estes aspectos, relativos aos quais Schön não exprimiu uma contribuição específica, pode ser interessante levar em consideração as experiências formativas aprimoradas em perspectiva sócio-construtivista e, em particular, a contribuição da pedagogia interativa, desenvolvida pelo Cresas $^{2}$, e as pesquisas-formação conduzidas no horizonte da didática profissional (Pastré, 2012).

\section{Pensamento Reflexivo e Grupo de Trabalho}

Se até agora nos ocupamos de uma epistemologia da prática profissional, nas próximas considerações vamos investigar a possibilidade de uma formação baseada em uma epistemologia da prática cultural, ou seja, da prática que tem como alvo não só um único profissional, mas o grupo de trabalho a que pertence profissionalmente. Tomando esta direção, a questão torna-se mais complexa para incluir, por um lado, as questões de ordem cultural, pertinentes às modalidades diante das quais um grupo constrói formas de troca de experiências, práticas educacionais, valores e conhecimentos sobre educação e gestão de uma instituição educativa que permitem atuar de forma eficaz e consistente; e outro lado, para explorar as condições e os modelos formativos destinados a apoiar grupos de trabalho deste complexo de competências.

A questão, portanto, se refere à possibilidade de explorar o trabalho formativo sobre as práticas pensadas a partir da possibilidade de recordá-las retrospectivamente para revê-las e não através dos olhos de um único profissional, mas ativando um nível de análise que envolve todo o grupo de trabalho. A abordagem de pesquisa-formação elaborada pelo Cresas (2000) e pelas bem conhecidas pesquisas de Sinclaire (1982) avança nesta perspectiva e, a partir de uma visão pós-piagettiana do desenvolvimento da criança, delineia o horizonte das práticas formativas, em consonância com uma pedagogia interativa, enraizada na observação e compreensão das experiências das crianças. 
O dispositivo formativo que deriva disso valoriza de forma decisiva o papel do grupo como contexto de aprendizagem e de formação com base em uma suposição metodológica subjacente: "constrói-se coletivamente antes de demolir, e não o contrário” (Hardy, 2004, p. 135)33. E, em particular, no modelo formativo em questão se constrói a partir do pressuposto de uma pedagogia construtivista: é com estas lentes que intervenções educacionais voltadas ao grupo de educadoras de uma instituição educacional levam a considerar as práticas profissionais que se tornam objeto de formação em vários níveis, seja analisando em grupo situações e casos expostos pelas próprias educadoras, seja estimulando o confronto a partir de documentações (protocolos de observação ou filmagens) fornecido pelos formadores e proposto com a intenção de aproximar o grupo aos princípios da pedagogia construtivista, ou seja, com o objetivo de promover um olhar sobre as práticas educativas voltadas para capturar as interações, inclusive as espontâneas, das crianças, a fim de compreender o desenvolvimento de sua aprendizagem. Através da análise e da microanálise ${ }^{4}$ de sequências educativas, que propõem ao grupo dinâmicas ocorridas no interior da instituição educacional, abrem-se no grupo reflexões críticas e apresentam-se perguntas em torno das condições educacionais que podem sustentar e facilitar a implementação de intervenções educativas orientadas em termos construtivistas. Define-se assim um contexto formativo em que o grupo, num envolvimento direto das educadoras, analisa as práticas profissionais postas em ação, explora suas possíveis razões e intencionalidade, investiga e discute os êxitos e as dinâmicas da conduta educacional no campo de atuação, analisa casos e problemas. Em particular, o grupo se torna a sede para fazer emergir e discutir as intenções perseguidas pelas educadoras na implementação de certas práticas educativas; o papel dos adultos e das crianças envolvidas; a organização (material, espacial, temporal); desenvolvimento da atividade; efeitos, reincidência, desdobramento eventuais (desejados, previstos). As práticas educativas são então reexaminadas a posteriori, com a intenção de desconstruir a instituição educativa que as fundamentou. Um papel essencial, evidentemente, é desempenhado neste processo pelo formador, que tem a função de orientar e promover a discussão e o debate, ajudar a explicitar as várias dimensões que compõem um caso ou um problema exposto, apoiar o aparecimento das dimensões teóricas, muitas vezes não expressas ou não completamente explícitas e, ainda, de permitir a expressão de divergências ou diferentes pontos de vista, ampliando a perspectiva de análise, usando novas chaves de leitura. O que provoca este tipo de treinamento? Induz o grupo educacional, após ter examinado e refletido de forma retrospectiva a prática educativa efetuada, a aperfeiçoar a atividade educativa, elaborar novas situações para experimentá-las na prática. Trata-se, portanto, de um proceder formativo que tematiza as práticas educativas para retornar. Na mesma direção, também a didática profissional identifica a centralidade da dimensão do grupo e da discussão dialética sobre as práticas profissionais dentro do grupo. 
Qual Formação no Trabalho Educativo com a Primeira Infância?

O trabalho não é percebido como o desempenho de uma tarefa, como a realização de uma função atribuída; não é a execução de procedimentos pré-definidos, mas envolve o desenvolvimento, mais ou menos livre e criativo, atividades transformadoras que mudam a realidade e os próprios indivíduos no trabalho. "O trabalho humano não se reduz a um simples meio necessário para a vida. Com o trabalhar o homem transforma o real, mas também transforma a si mesmo" (Pastre, 2012, p. 64). É evidente nesta citação, o eco do pensamento marxista. Esta maneira de conceber as dimensões do trabalho abre o caminho para visualizar as dimensões da formação potencialmente, características da ação profissional para afirmar não só que o trabalho se aprende trabalhando, mas também que no trabalho se pode aprender, se pode crescer e evoluir como indivíduos. "Trabalho significa utilizar como recursos para a ação um conjunto de conhecimentos. Trabalhar é, portanto, conhecer e não simplesmente aplicar os conhecimentos adquiridos" (Bruni; Gherardi, 2007). Se o trabalho é uma dimensão na qual os cidadãos exercem o pensamento, a inteligência, investem recursos emocionais e criativos, faz sentido analisar as práticas profissionais, investigar a forma como o trabalho é organizado e conduzido. E esta análise é feita trazendo à tona, na dimensão de grupo, as práticas profissionais (documentadas por meio de protocolos de observação ou filmagem), que pode ser revisitadas fazendo emergir os padrões de ação, os conhecimentos operativos construídos no campo de atuação, que apoiam e orientam ação profissional (Vergnaud, 1996; 2007). Esta abordagem tem sido amplamente desenvolvida na análise das práticas de ensino/aprendizagem (Altet; Charlier; Paquai; Perrenoud, 2006; Vinatier; Altet, 2008; Vinatier, 2009), contemplando a análise e a discussão subsequentes na dimensão de grupo, de sequências específicas de ação e comunicação em contextos em que professores e alunos compartilham contextos de ensino/aprendizagem, e permitindo a reformulação crítica de escolhas e estratégias, até mesmo verbalmente, com vista a uma reformulação mais consciente.

Uma vez mais, volta à tona a finalidade de transformação da formação, o objetivo de apoiar e promover a mudança das práticas com base na análise das próprias práticas. É útil, portanto, deter-se neste ponto sobre as dinâmicas que um grupo profissional encara ao percorrer o caminho que separa a análise das práticas realizadas na retaguarda, em situações de suspensão de ação, em um espaço-tempo dedicado de pensamento, a partir da implementação de novas práticas de trabalho, redesenhadas no grupo de trabalho.

Entre o plano de formação, definido para a análise da prática através da evocação e discussão em grupo, e a realidade da prática educativa na atuação, há uma lacuna, um espaço vazio, que deve ser preenchida de significados pelo grupo para traduzir em prática educativa e mudança efetiva as reflexões e pensamentos compartilhados com a orientação do formador. E sobre essa passagem, do plano de formação 
à realidade prática, torna-se útil deter o olhar, definindo um problema a refletir, uma vez que tal momento é muitas vezes experienciado pelas educadoras com grande desconsideração e como uma passagem quase intransponível. Ao se definir um problema a refletir nessa passagem, em muitas circunstâncias, os grupos de trabalho mostram grandes recursos educacionais reflexivos e vontade de se envolver, revendo também criticamente situações educativas ocorridas com a intenção de reconsiderá-las atribuindo um novo significado a acontecimentos subestimados ou talvez interpretados de acordo com a lógica da repetição e do mecanicismo.

Essas dimensões reflexivas sobre as ações educativas ocorridas são recorrentes em contextos formativos destinados a educadoras, como no exemplo a seguir:

Formador: Eu notei que no canto onde as crianças têm à disposição uma cozinha, alguns pratos e copos... há uma prateleira na parte superior, que as crianças não podem alcançar e lá em cima há uma de cafeteira e algumas xícaras ...

Educadora 1: sim, assim as crianças podem brincar com materiais diferentes, quando eles querem as coisas colocadas na prateleira nós as pegamos e as damos a eles.

Educadora 2: Para nós, é importante que as crianças aprendem a pedir os brinquedos.

Educadora 3: também serve para evitar demasiada confusão, materiais em excesso que se acumulam e não ajudam a brincadeira, mas distraem as crianças que, na confusão, ficam nervosas, se cansam e param de brincar.

Formador: então a intenção de vocês é evitar a confusão?

Educadora 1: sim, as crianças na confusão, ficam agitadas, na confusão que eles criam confusão, levantam o tom de voz...

Formador: e como se concilia esta escolha àquela de apoiar a autonomia das crianças que vocês me disseram ser um de seus objetivos educacionais?

Educadora 2: as crianças sabem que certos brinquedos estão à disposição e que outros podem pegar, pedirem, eles aprenderam.

Educadora 1: na verdade, as crianças são dependentes de nós educadoras, elas não podem pegar o que querem.

Educador 3:... mas uma cafeteira e algumas xícaras de café a mais... não fazem tanta confusão.

Educadora 1: então o que colocaremos na prateleira?

As reflexões desenvolvidas pelas educadoras, a pedido do formador, podem ter como desdobramento levar em consideração, no espaço hipotético do pensamento e da prefiguração, outras formas possíveis de pensar e organizar o espaço e os materiais, para estruturar a área projetada para as brincadeiras das crianças, chegando à redefinição do papel atribuído às próprias crianças. Mas esses pensamentos que surgem em torno de uma mesa, longe do trabalho educativo com as crianças e a necessidade de fazer escolhas em tempo real, como podem se conectar e desenrolar-se efetivamente no mundo da ação e intervenção na prá- 
Qual Formação no Trabalho Educativo com a Primeira Infância?

tica, no concreto e caótico aqui e agora? Como evoluem e como se materializar na mudança real os modos de se estar e agir com as crianças conscientemente? Estas medidas, que também podem ser exploradas e projetadas "à mesa” com a ajuda do formador, de fato, tomam forma ao longo das outras etapas de meditação e tradução em operação, que as educadoras e o grupo profissional conduzem (se conduzem) prevalentemente em modo autônomo.

E esta discrepância é frequentemente relatada, com ênfase na crítica, pelas próprias educadoras que marcam a diferença entre o que emerge da chamada teoria e o que, ao contrário, caracteriza a ação educativa real, durante a qual muitas vezes se verifica que o que funciona, que tem um efeito benéfico sobre fluir das relações entre as crianças ou entre educadora e criança, não é suportado por nenhuma teoria específica, mas pela experiência das educadoras, que interiorizaram segurança e orientação profissional no trabalho prático. Muitas situações educacionais que caracterizam o fluxo habitual da vida da creche (a recepção das crianças na parte da manhã, por exemplo, ou ainda os momentos de transição entre o fim de uma atividade e o início de uma outra) não são suportadas por uma teoria de referência específica, mas envolvem a ativação de recursos educativos por parte da equipe da creche, que manifesta o seu próprio planejamento educacional, sua própria cultura pedagógica que em grande parte se realiza e se configura enquanto o pensamento está em ação.

O famoso quadro de René Magritte, Ceci n'est pas une pipe (Isto não é um cachimbo), resume, melhor do que qualquer reflexão, esta lacuna epistemológica, levando a entender, com a densidade impressionante de uma imagem, quanto à representação não é a coisa representada. Assim como na obra de Magritte, o cachimbo representado não é um cachimbo, da mesma forma, a análise das práticas e a replanificação pensada das práticas não são as práticas, é uma outra coisa em relação às práticas pedagógicas. Se com formação entende-se aproximar-se e dar valor às dimensões de consciência e de pensamento educativo aprimorados na prática e nas ações das educadoras no campo de atuação, então é necessário criar dispositivos formativos mais dinâmicos e dialéticos, abertos à experimentação e ao risco de uma maior aproximação aos processos educativos que acontecem no campo, capazes de redefinir a configuração, o conteúdo e os métodos para reduzir a lacuna que muitos modelos de formação criam entre as práticas no campo de atuação e a análise das práticas.

Surge assim, a necessidade de esclarecer e refletir sobre qual conexão e quanta proximidade se deseja atribuir à dimensão educativa em relação a das práticas profissionais em vigor nas instituições e no grupo de trabalho. Nesse sentido, ao lado de modelos e práticas de formação de caráter reflexivo, destinados a explorar e estimular a expressão dos pensamentos e as intenções do pessoal docente, podem encontrar espaço modelos de formação que se movem no campo e que

996 Educação \& Realidade, Porto Alegre, v. 40, n. 4, p. 987-1004, out./dez. 2015. 
se destinam a apoiar as educadoras em percursos de experimentação de novas práticas profissionais, a serem definidas e não pensadas $a$ posteriori, quando a atividade educacional já ocorreu e terminou, mas no momento em que a intervenção e, concomitantemente, o trabalho educativo estão em andamento, isto é, quando a ação profissional está em ação e as educadoras estão na atividade.

Não se trata, de tal forma, de efetuar hipoteticamente modelos de formação alternativos aos descritos até agora, mas admitir tanto a necessidade de ativar um pensamento reflexivo sobre as práticas quanto contextualizar na dinâmica do grupo a reflexão sobre as práticas em si, para testar os modelos e processos de formação que integrem estas abordagens e escolham percorrer caminhos formativos mais estreitamente ancorados na prática, no qual o conhecimento prático toma forma no trabalho educativo.

\section{Quem Forma Quem?}

Nasce a partir dessas premissas a ideia de ativar processos de aprendizagem destinados a docentes, enquanto estão no trabalho, no fluxo diário de práticas e ações que configuram os períodos educacionais oferecidos às crianças que estão presentes na instituição educativa. A hipótese assumida é a de que para entender as práticas educacionais efetivamente desenvolvidas na creche, por exemplo, relativas aos momentos de recepção da manhã, e também as propostas lúdicas destinadas às crianças, seja importante reduzir a distância que tradicionalmente separa a formação cotidiana do trabalho educativo, prevendo, então, uma presença formativa para trabalhar ao lado das educadoras, enquanto elas estão no trabalho. A referência a teorias de aprendizagem guiada (Rogoff, 1990) e ao conceito de tutela proposto por Bruner (Wood; Bruner; Ross, 1976) são óbvias.

Por que mudar a formação da sala de aula para a prática? Em grande parte por causa da exigência de implementação de processos de formação destinados não só para a compreensão das práticas educativas, mas também para sua transformação, para a mudança segundo modalidades não arbitrariamente introduzidas de fora ou de cima, mas em formas compartilhadas pelo grupo educacional que participa da formação. Sob este ponto de vista, alcança-se uma conexão dinâmica entre a formação e cultura pedagógica - organizadora da creche (Agliati; Infantino, 2010), e a formação não é pensada como parênteses, separada da conduta normal do trabalho, com a intenção de introduzir os conhecimentos e pressupostos teóricos pré-existentes, mas se acredita, pelo contrário, que nos grupos de trabalho já existam formas de conhecimento, competências profissionais, práticas especializadas que têm a sua própria história, seu próprio significado, o seu próprio valor e são, portanto, aceitas, nominadas, sistematizadas, sustentadas para que possam ser capitalizadas e levadas a novos desenvolvimentos, 
Qual Formação no Trabalho Educativo com a Primeira Infância?

mesmo em termos de mudança. O objetivo não é apenas para aumentar o nível de conhecimento e consciência no pessoal docente da educação, mas também (ou sobretudo?) para promover um contato real por parte das educadoras e professores, individualmente e dentro do grupo educativo, das modalidades mediantes às quais se interpreta o seu papel e colocam em ação as práticas educativas concretas, a fim de enriquecer, ampliar a complexidade, alterá-las, se forem considerados ineficazes ou incompatíveis com os propósitos educacionais que animam o projeto pedagógico da instituição.

Colocar formação nas práticas e prever sessões de formação não separadas do real desenrolar dos dias normais na creche e das exigências formativas usuais de interação entre educadoras, crianças, e pais, significa trabalhar em direção a processos formativos situados (Zucchermaglio; Alby, 2006), uma medida de características e as necessidades específicas de formação de cada grupo de trabalho, excluindo a proposta de pacotes e conteúdos padrão ou pré-definidos; implica a escolha de modelar e modular a formação em constante diálogo com a comunidade profissional que participa (Lave; Wenger, 1991).

Deste pressuposto derivam algumas consequências metodológicas importantes. A principal diz respeito à figura do formador. $\mathrm{Na}$ formação tradicional (e, geralmente, também nos modelos considerados até agora) o formador é geralmente um especialista disciplinar com competências definidas em áreas específicas da cultura sobre a primeira infância, e a sua possibilidade de desenvolver programas de formação baseados justamente no complexo de conhecimentos científico que é capaz de organizar em percursos de aprofundamento sobre núcleos temáticos definidos, utilizáveis para as educadoras. É de fato essencialmente um teórico. No entanto, quando a formação sai da sala de aula para colocar-se no campo de atuação, o formador tradicional, que se baseia em um conhecimento de natureza conceitual, deixa espaço para uma outra figura formativa, com habilidades específicas e sólidas competências na dimensão do saber prático. Para desenvolver intervenções formativas capazes de dialogar com as práticas que as educadoras implementam é de fato necessário ter uma experiência profissional bem estabelecida, própria de quem aperfeiçoou uma sólida competência educativa e, por esta razão (e não por uma razão de status) constrói uma posição de autoridade em relação ao grupo educativo em formação. São, portanto, educadoras experientes e figuras capazes de intervir no contexto dos processos de formação, definindo, assim, uma nova figura de formação, prática. O critério que define o perfil de uma educadora especialista não é o tempo de serviço, mas a qualidade e maturidade alcançada ao longo da experiência profissional, o que leva ao desenvolvimento de habilidades de pensamento reflexivo, a posicionar-se diante de questões e de problemas que surgem no campo, referindo-se a uma extensa gama de modalidades, da qual extrai informações de forma flexível. É neste ponto necessário fazer um esclarecimento: o

998 Educação \& Realidade, Porto Alegre, v. 40, n. 4, p. 987-1004, out./dez. 2015. 
formador prático não é um tutor de empresa, ou seja, não é o membro considerado mais competente da organização para a qual trabalha, e, portanto, responsável por funções de orientação, formação profissional em relação a figuras menos experientes. É uma figura externa, não tem um papel na estrutura organizacional e em virtude desta distância está em uma posição para relatar novos pontos de vista, para apresentar incômodos, provocações criativas e inovadoras nos padrões habituais das educadoras, que correm o risco de se tornarem repetitivas rotinas, vazias de significado. Ele não introduz um método de ensino ou de um padrão pedagógico pré-definido, o seu objetivo é mais aquele de apoiar as educadoras para identificar e adotar as práticas que consideram mais eficazes, apoiando a experimentação concreta de novas modalidades de intervenção, se necessário, também mostrando e oferecendo formas alternativas às já conhecidas, mas sem a introdução de nenhuma, em particular. Ele se move como um observador que, com discrição, aproxima-se da realidade que observa para lançar perguntas sobre o óbvio, tornando-o assim menos óbvio e previsível do que parece às educadoras que o utilizam. Ele mostra às educadoras que se pode assumir novas perspectivas sobre as crianças e o papel desempenhado pelas próprias educadoras no seu modo de ser e de agir com as crianças.

É um formador que não usa as palavras, mas forma com sua intervenção, aproximando-se da ação das educadoras para expandi-la, potenciá-la (Infantino, 2012; Infantino, 2014). Se a formação tradicional corre ao longo de uma sequência de teoria-prática-teoria, na formação na prática educativa, a escolha é de apoiar os processos que partem da prática e voltar a ela, em dinâmica circular prática-teoria-prática.

\section{A Formação Prática na Área de Atuação}

É necessário, neste ponto, introduzir com maior precisão algumas etapas do processo de formação até agora delineadas para melhor expor o significado desta proposta e, especialmente, para definir mais detalhadamente as peculiaridades das funções desempenhadas pelo formador prático.

Note-se que, em comparação aos tempos pré-definidos da formação tradicional, a formação prática requer o desenvolvimento de uma série de etapas ou fases que precedem a formação no próprio campo, que preveem o envolvimento, além das educadoras, dos gestores das instituições e dos coordenadores para definir de forma preliminar, as condições de possibilidade, os limites e os recursos que, juntos, circunscrevem o perímetro no qual o processo educacional poderá tomar forma. Segue-se uma fase de progressiva e gradual presença do formador para observar no interior da creche, com tato e discrição, as formas de abordagem das educadoras comprometidas com o trabalho, a fim de garantir o desenvolvimento de uma relação fluida, livre do medo do julgamento. $\mathrm{O}$ formador prático irá realizar suas intervenções estando em 
Qual Formação no Trabalho Educativo com a Primeira Infância?

contato direto com as educadoras, observando seus gestos, seus movimentos, a dinâmica com e entre as crianças, tudo, longe de ser óbvio e emocionalmente neutro, pode ser feito gradualmente, se as educadoras percebem o potencial formativo de tal dinâmica e aceitam entrar nesse jogo, sentindo que podem confiar no olhar e na presença de um formador que está em campo. Este clima de confiança mútua e acessibilidade deve ser construído e os primeiros passos que o formador dá na área de atuação, a maneira com que ele se insere no quotidiano educativo são determinantes sob este ponto de vista. O início deste contato formativo é feito recolhendo material de observação e identificação das dimensões educativas sobre as quais se vai construir uma atenção compartilhada com o grupo de educadoras. É, por exemplo, assim que um formador recolhe os primeiros elementos no decurso de uma sequência observada em uma creche:

Grupo de 8 crianças entre 24-32 meses, com uma educadora.

A educadora convida as crianças a arrumar a sala antes do lanche, está de joelhos sobre o tapete, coloca alguns brinquedos no cesto, então, dirige-se às crianças, apontando com o dedo os brinquedos que devem ser guardados. As crianças os recolhem e os arrumam em seus cestos. A professora se desloca para outro canto. Está sozinha e começa a recolher o material de jogo espalhados no tapete, alguns segundos depois chegam quatro crianças que recolhem os jogos. Na hora do lanche estão sentadas à mesa seis crianças, a educadora mostra e cheira uma maçã verbalizando todas as suas ações. Descasca a maçã, as crianças esperam e observam, alguém diz 'pera'. As crianças se servem sozinhas pegando as fatias de maçã da cesta. Terminado o lanche as crianças se deslocam, algumas sobem as escadas alternando os pés.

Em outro momento do dia com outra professora:

Anna penteia os cabelos com a escova e se olha no espelho, aproxima-se Paul. Ana escova os cabelos de Paul. Paul se senta, mantém a cabeça firme, enquanto Anna continuou a escovar seus cabelos. Gaia chega, empurra Paul, senta-se em seu lugar, a interação entre as crianças se desestrutura.

A professora está presente, observa a cena e não intervém.

Estas observações iniciais, coletadas da prática educativa, são propostas pelo formador ao grupo educativo para começar a compartilhar perspectivas, dar forma e nome aos problemas, evidenciar intervenções educativas, fazer conexões entre as práticas efetuadas e o projeto pedagógico declarado que, no caso da instituição em questão, tem o foco no valor da autonomia das crianças. Emergem falhas, linhas de fragilidade e incoerências, percebidas e relatadas pelas próprias educadoras que se interrogam sobre as intervenções educativas, mas também sobre o significado da não-intervenção, e escolhem orientar a formação como apoio ao papel educativo, para definir com maior partilha e clareza os âmbitos, as estratégias, as dinâmicas que gostariam de adotar em grupo nas intervenções destinadas às crianças. Compartilhado este plano, o trabalho de observação do formador continua com um propósito mais claramente definido, que gradualmente levará a uniformizar

1000 Educação \& Realidade, Porto Alegre, v. 40, n. 4, p. 987-1004, out./dez. 2015. 
a formas de ação formativa mais explícitas e diretas, em cooperação com as educadoras em suas interações com as crianças.

Este maior foco do formador sobre o papel da educadora emerge no passo seguinte:

Tive a oportunidade de observar a educadora em muitas situações e, em quase todas, estava sentada no chão. Percebi que, por vezes, não percebia algumas das dinâmicas entre as crianças não por incompetência, mas porque é inegável que sentada no chão a perspectiva é bastante diferente. O seu modo de entrar em relação com as crianças é muito física que, em si, não é 'errado', mas não devemos esquecer que uma das tarefas da educadora, declarada no projeto educativo desta instituição é ajudar as crianças a manter e expandir sua capacidade de autonomia. A tal propósito, pode se usar diferentes recursos: os materiais, os brinquedos, os espaços e certamente também a postura a posição no espaço da própria educadora. Neste caso, o objetivo formativo compartilhado com a educadora era trabalhar sua postura e sua distância no relacionamento com as crianças, tendo em consideração as necessidades e as competências delas no que diz respeito à autonomia. Em particular, minhas intervenções tiveram o objetivo de levantar do chão a educadora para experimentar uma postura diferente, não mais sentada no tapete, mas em uma cadeira.

Para o formador trata-se, então, de identificar as modalidades de intervenção formativa não-invasivas e desvalorizantes, mas ao mesmo tempo explícitas, que possam ajudar a educadora em questão a reformular sua forma de relacionar-se com as crianças a partir da capacidade de perceber de forma mais dinâmica e flexível as necessidades delas, para calibrar distâncias e estabelecer uma forma de contato com as crianças que não se limite apenas ao contato físico, mas que ative, flexível e variável, dependendo da situação, outros canais e outras estratégias possíveis.

De fato, as práticas educativas implementadas pela educadora resultam claramente deste protocolo de observação:

Grupo de crianças entre 12 e 18 meses, com uma educadora.

A educadora está sentado com as pernas cruzadas, com Anna em seu colo, com as costas apoiadas em seu peito. A criança pega uma pinha, a educadora inclina a cabeça para a frente para poder olhá-la, acaricia seu rosto e lhe dá um beijo, a menina segurando a pinha. A educadora estende as pernas e a menina se senta no chão, mantendo-se entre as pernas da educadora, sempre apoiada sobre seu corpo. A educadora dobra uma perna para trás e a menina se move a manter contato com o corpo da educadora. Luca chega correndo, a educadora se afasta de Anna para pegá-lo. Anna tenta se reaproximar do corpo da educadora, que porém levanta pegando Lucas no colo. Anna então se move para um armário baixo, pega um brinquedo de encaixe de madeira com o formato de uma torre e observa que a educadora está ocupada com Luca.

Enquanto isso, o formador está sentado em um banco na frente da educadora, sentada na frente do formador está Mara, que coloca em uma cesta algumas pinhas, fitas, correntes. Troca de olhares entre Mara 
Qual Formação no Trabalho Educativo com a Primeira Infância?

e formador. $\mathrm{O}$ formador oferece à criança um cubo de madeira, Mara imediatamente coloca-o na cesta e olha para o formador que, em segui$\mathrm{da}$, oferece mais um cubo à menina que o coloca na cesta. $\mathrm{O}$ formador agita uma tampa de lata, que produz um tinido com uma corrente contida em seu interior. Mara observa, estende a mão para pegar a tampa, a sacode, pega a corrente e a faz ondular.

O comportamento adotado pelo formador tem claramente a intenção de mostrar e oferecer à educadora a oportunidade de escolher entre várias estratégias para interagir com as crianças, assim como a física, concentrando-se no papel de mediação que podem desempenhar materiais e objetos colocados à disposição ou oferecidos às crianças pelo adulto. Esta modalidade, que não é melhor ou mais correta do que as outras, poderia permitir que a educadora nesta situação, se oferecesse como presença atenta ao pequeno grupo de crianças que se está formando, sem concentrar a sua atenção exclusivamente ora a uma criança, ora a outra, criando assim, como veremos no próximo protocolo, uma sensação de espera passiva, em quem se encontra sozinho.

Anna estava sentada atrás da educadora, que agora está de volta ao tapete com Lucas no colo. Quando a educadora se move Anna também move para ficar perto dela. Luke se senta ao lado de Mara. Anna se aproxima da educadora que olha para ela, abraça-a e a pega no colo até que chega Lucas que também encontra espaço para se sentar em seu colo.

A este ponto, o formador decide entrar na cena de uma maneira direta. Ele propõe à educadora mudar de posição e sentar-se em uma cadeira baixa. A dinâmica que toma forma registra imediatamente uma mudança no cenário e no equilíbrio das relações.

Quando a educadora se senta na cadeira, Anna se aproxima e se senta no chão a uma curta distância, de costas para ela. Olha os brinquedos de madeira sobre o tapete, toca um brinquedo de encaixe, pega e começa a empilhar as rodelas. Concentra-se nestes materiais.

Para a educadora a oportunidade de experimentar uma forma diferente de estar com as crianças significa concretamente tentar agir diferente e testar a utilidade e a eficácia de uma maior lucidez na gestão da distância e do envolvimento nas interações com as crianças. Tentar agir de outra maneira tem o grande valor de expandir o leque de possibilidades para a ação, e instiga a elaborar um pensamento menos rígido sobre as crianças.

No momento de confronto entre formador e educadora, que ocorreu em seguida à sequência analisada, a educadora fez este comentário que, como conclusão deste artigo, exemplifica o valor dos processos formativos diretamente no campo de atuação de acordo com um desenvolvimento prática-teoria-prática:

Percebi nessa situação com Anna que eu criei um pouco de dependência. Devo acompanhar Anna a fazer outra coisa. É importante trabalhar a distância. Nenhum livro poderia me ensinar isto de forma tão eficaz.

1002 Educação \& Realidade, Porto Alegre, v. 40, n. 4, p. 987-1004, out./dez. 2015. 
Optamos por explorar no campo de atuação a oportunidade de experimentar novos modelos de formação voltadas a valorizar a experiência das educadoras e reconhecer a dignidade do saber e do conhecimento educativo que surgem na prática profissional. É um caminho interessante, certamente não o único. E, como tal, merece ser percorrida e investigada.

Recebido em 18 de novembro de 2014 Aprovado em 12 de maio de 2015

Revisão Técnica da Tradução: Ligia Maria Leão de Aquino

\section{Notas}

1 Farei referência à formação em serviço do pessoal educativo e não à formação de base ou universitária que, em relação às considerações que seguirão neste artigo, solicitaria uma declinação específica em razão das peculiaridades que a caracterizam.

2 Il Cresas, ou seja, Centre de l'Éducation Spécialisé et de l'Adaptation Scolaire dell'INRP (Intitut National de Récherche Pèdagogique), desenvolve desde os anos 70 pesquisas e atividade formativa sob a ótica de combater o insucesso escolar a exclusão, assumindo os seguintes interrogativos: como favorecer o aprendizado para todos as crianças? Como organizar as instituições educativas para que as crianças possam colocar em prática as suas capacidades de aprendizado e desenvolver percursos de aprendizado específicos para cada um?

3 Traduzido do francês pela autora, ora trazido para o português.

4 A micro-análise é uma modalidade de observação utilizada em pesquisa que examina sequências de interação entre crianças filmadas geralmente em contextos educativos para a infância. A ideia que move a pedagogia interativa é que as crianças são ativas construtoras de seu aprendizado e que as interações entre crianças, e não só com o adulto, falicitam a criação de saberes desde a mais tenra idade. As técnicas de microanálise permitem um exame acurado e minucioso da ação abrindo a possibilidade de iniciar confronto e discussão no grupo em formação.

\section{Referências}

AGLIATI, Alessia; INFANTINO, Agnese. Fare e Pensare: la formazione come cultura. In: ZANINELLI, Francesca (Org.). Pedagogia e Infanzia. Milano: Franco Angeli, 2010.

ALTET, Marguerite; CHARLIER, Eveline; PAQUAI, Léopold; PERRENOUD, Philippe. Former des Enseignants Professionnels: quelles strategies? quelles compétences? Paris: De Boeck \& Larcier, 1996.

BARBIER, Jean-Marie. L'Analyse des Pratiques: questions conceptuelles. In: BLANCHARD-LAVILLE, Claudine; FABLET, Dominique. L'Analyse des Pratiques Professionnelles. Paris: L'Harmattan, 2000. P. 35-58.

BOURDIEU, Pierre. Le Sens Pratique. Paris: Editions de Minuit, 1980.

Educação \& Realidade, Porto Alegre, v. 40, n. 4, p. 987-1004, out./dez. 2015.1003 
Qual Formação no Trabalho Educativo com a Primeira Infância?

BRUNI, Attila; GHERARDI, Silvia. Studiare le Pratiche Lavorative. Bologna: Il Mulino. 2007.

CRESAS. On n'Enseigne pas Tout Seul: à la crèche, à l'école, au college et au lycée. Paris: INRP, 2000.

HARDY, Marianne. Observer les Enfants pour Amènager les Situations Éducatives. In: FABLET, Dominique. Professionelles de la Petite Enfance et Analyse de Pratiques. Paris: L'Harmattan, 2004. P. 133-162.

INFANTINO, Agnese (Org.). Pratiche Educative nei Servizi per l'Infanzia. Milano: Franco Angeli, 2014.

INFANTINO, Agnese. Estágio e Formação na Prática Pedagógica em Creches Públicas Italianas. Olh@res: Revista do Departamento de Educação da Universidade Federal de São Paulo - Unifesp, São Paulo, v. 01, n. 01, p. 7-39, 2012.

LAVE, Jean; WENGER, Etienne. Legitimate Peripheral Paricipation. New York: Cambridge University Press, 1991.

MORTARI, Luigina (Org.). Dire la Pratica: la cultura del fare scuola. Milano: Bruno Mondadori, 2010.

ROGOFF, Barbara. Apprenticeship in Thinking: cognitive development in social context. New York: Oxford University Press, 1990.

SCHÖN, Donald Alan. Educative the Reflective Practitioner: toward a new design for teaching and learning in the professionis. San Francisco: Jossey Bass, 1987.

SCHÖN, Donald Alan. The Reflexive Practitioner. New York: Basic Books, 1983. SCRIBNER, Sylvia. Mind and Social Practice. New York: Cambridge University Press, 1997.

SINCLAIRE, Hermine et al. Les Bébés et le Choses. Paris: PUF, 1982.

VERGNAUD Gérard. Au Fond de l'Action, la Conceptualisation. In: BARBIER, Jean-Marie (Org.). Savoir Théorique et Savoir d'Action. Paris: PUF, 1996. P. 29-42.

VERGNAUD, Gérard. Représentation et Activité: deux concepts étroitement associes. Recherche en Education, Nantes, CREN, n. 4, p. 9-23, 2007.

VINATIER Isabelle; ALTET Marguerite. Pour Analyser et Comprendre la Pratique Enseignante. Rennes: Presse Universitaire de Rennes, 2008.

VINATIER, Isabelle. Pour une Didactique Professionnelle de l'Enseignement. Rennes: Presse Universitaire de Rennes, 2009.

WOOD, David; BRUNER Jerome, ROSS, Gail. The Role of Tutoring in Problem-solving. Journal of Child Psychology and Psychiatry, Londres, v. 17, n. 2, p. 89100, 1976.

Agnese Infantino é pesquisadora de pedagogia geral e pedagoga social e professora de pedagogia da educação infantil Da Università Degli Studi Di Milano-Bicocca.

E-mail: agnese.infantino@unimib.it

1004 Educação \& Realidade, Porto Alegre, v. 40, n. 4, p. 987-1004, out./dez. 2015. 